\title{
Somut Olmayan Kültür Mirası (SOKÜM) ve Kadın
}

\author{
Intangible Cultural Heritage \& Women
}

\section{Gökçe ŞìŞ̧EK*}

Özet: Son zamanlarda, somut olmayan kültür mirasının (SOKÜM) üretilmesinde, korunmasında ve gelecek nesillere aktarılmasında toplulukların ana aktörlerinden kadının, rolü ve katkısına ilişkin uluslararası platformda önemli çalışmalar gerçekleşmektedir. Özellikle, Birleşmiş Milletler Eğitim, Bilim ve Kültür Teşkilatı (UNESCO)'nın gündeminde, somut olmayan kültür mirası ve kadının birlikte ele alındığını ve gerçekleştirilen toplantılarla bu alandaki gelişmelere yön verildiği bilinmektedir. Bugün dünyada kadına SOKÜM'ün korunmasında ve yaşatılmasında biçilen rolün anlaşılması açısından bu toplantılarda gerçekleştirilen tartışmaların ve varılan sonuçların eşsiz kaynaklar olduğu ortadadır. Bu çerçevede yazı, SOKÜM ve kadın konusunda uluslararası platformdaki gelişmelere ilişkin süreci UNESCO tarafından gerçekleştirilen çalışmaları temel alarak anlamayı amaçlamaktadır. Yazıda özellikle, bu konunun tarihsel gelişimini göstermesi bakımından önemli olduğu düşünülen 1999 Tahran 'Somut Olmayan Kültür Mirası'nın Aktarılmasında Kadının Rolü' başlıklı Uluslararası Sempozyum, 2001 Tahran' 'Kadın, Somut Olmayan Kültür Mirası ve Kalkınma' başlıklı uzmanlar toplantısı ve 2003 Paris 'Cinsiyet ve Somut Olmayan Kültür' başlıklı uzmanlar toplantısı belgeleri ve Somut Olmayan Kültürel Mirasın Korunması Sözleşmesi (UNESCO, 2003) üzerine yoğunlaşılacaktır. Bugün, UNESCO'nun 2012-2013 programında geliştirdiği stratejide, kültür alanında SOKÜM ve kadının birlikte toplumsal cinsiyet eşitliği bağlamında vurgulandığı düşünülürse, bu alanda yapılan çalışmaların insanlığın daha iyi bir gelecek kurmasında ve mutluluğunda önemli katkılar yaptı̆̆ı vurgulanmalıdır.

Anahtar sözcükler: Somut Olmayan Kültür Mirası, kadın, UNESCO, toplumsal cinsiyet eşitliği

\begin{abstract}
Recently the role and contribution of women, as the principal actors of community in the transmission and safeguarding of intangible cultural heritage have been studied on an international scale. In particular, the United Nations Educational, Scientific and Cultural Organization (UNESCO) focuses upon the significant role of women in relation to intangible cultural heritage and produces new developments through the meetings and discussions. The results of the meetings and discussions are valuable and unique sources for understanding the historical development process of issues and concepts in the field of intangible cultural heritage and women. Within this scope, this paper aims to analyze the process and improvements in the field of intangible cultural heritage and women through documents and the discussions at UNESCO meetings. It focuses on four main UNESCO works; (1) 'International Symposium on the Role of Women in the Transmission of Intangible Cultural Heritage' (1999, Teheran), (2) 'Women, Intangible Heritage and Development' (2001, Teheran) and (3) Gender and Intangible Cultural Heritage (2003, Paris) and (4) the Convention for the Safeguarding of the Intangible Cultural Heritage (UNESCO, 2003) that can be viewed as milestones in improvements in this field. Today, considering UNESCO's focus upon the empowerment of women in relation to intangible cultural heritage through the global strategy in culture, the studies have great contributions for the prosperity and happiness of communities for a better future for humankind.
\end{abstract}

Keywords: Intangible Cultural Heritage, women, UNESCO, gender equality

\footnotetext{
* Yrd. Doç. Dr., Adnan Menderes Üniv., Fen-Edebiyat Fakültesi, Sanat Tarihi Böl., Aydın, gokce.simsek@adu.edu.tr
} 
İnsanlığın sözel kültürel belleğindeki birikim, Birleşmiş Milletler Eğitim, Bilim ve Kültür Teşkilatı (UNESCO) tarafından Somut Olmayan Kültürel Miras (SOKÜM) olarak adlandırılmaktadır. Bu mirasın gelecek kuşaklara aktarılması için korunması gerektiği yaklaşımı çerçevesinde 17 Ekim 2003 tarihinde UNESCO Genel Kurulu'nda, Somut Olmayan Kültürel Mirasın Korunması Sözleşmesi kabul edilmiş, Türkiye 2006 yılında taraf olmuştur, (http://aregem.kulturturizm.gov.tr/TR,13223/unesco-somut-olmayan-kulturel-miras-calismalari.html. Türkiye/01.08. 2012). Sözleşme'de SOKÜM, "toplulukların, grupların ve kimi durumlarda bireylerin, kültürel miraslarının bir parçası olarak tanımladıkları uygulamalar, temsiller, anlatımlar, bilgiler, beceriler ve bunlara ilişkin araçlar, gereçler ve kültürel mekânlar anlamına gelir" (http:// www.unesco.org.tr/?page=11:129:5:turkce, 28.07.2012). Oğuz'a göre (2009, 8) bu sözleşme, “... bir toplumun kendi kültürel kimliğinin bir parçası olarak gördüğ̈̈ ve kuşaktan kuşağa aktarmak suretiyle günümüze kadar getirdiği somut olmayan kültürel miraslarının korumasına ve gelecek kuşaklara aktarmasına katkı sağlayacak yol, yöntem ve imkânları tanımlamaktadır" SOKÜM'ün küreselleşme, sosyal dönüşümler, kaynakların yetersizliği gibi günümüz süreçleriyle bozulma, yok olma veya yıkılma tehdidi altında olduğu belirtilir. Özellikle toplumların, grupların, bazı durumlarda bireylerin SOKÜM'ün üretilmesinde, korunmasında, bakımın da ve yeniden üretilmesinde önemli rolleri olduğu vurgulanır (http://www.unesco.org/ culture/ich/doc/ src/00125-EN.pdf/ 01.08.2012). Bu önemli rolde, kadının katkısını ve yerini küçümsemek mümkün değildir. Özellikle, hikâyeler, ninniler, halk oyunları, doğum, evlenme, ölüm, şenlik, bayram, halkmutfağı, halk mimarisi gibi SOKÜM'ün çeşitli alanlarını (Oğuz, 2009) düşündüğümüzde, kadın bu mirasın gelecek kuşaklara aktarılmasında yadsınamayacak önemde bir role sahiptir.

SOKÜM'ün korunmasında ve gelecek kuşaklara aktarılmasında kadının taşıdığı önemli rol UNESCO önderliğinde gerçekleştirilen toplantılarla uluslararası toplumun gündemine getirilmiştir. Özellikle konunun tarihsel gelişimini göstermesi bakımından üç ana toplantı; ilki, 1999'da Tahran'da 'Somut Olmayan Kültür Mirası'nın Aktarılmasında Kadının Rolü' (International Symposium on the Role of Women in the Transmission of Intangible Cultural Heritage) başlıklı Uluslararası Sempozyum, ikincisi, 2001'de Tahran'da 'Kadın, Somut Olmayan Kültür Mirası ve Kalkınma' (Women, Intangible Heritage and Development) başlıklı uzmanlar toplantısı ve üçüncüsü, 2003'de Paris'te 'Cinsiyet ve Somut Olmayan Kültür Mirası' (Gender and Intangible Cultural Heritage) başlıklı uzmanlar toplantısı olarak gerçekleştirilmiştir. Belirtilen çerçevede bu çalışma, SOKÜM'ün aktarılmasında ve korunmasında kadının rolüne ilişkin uluslararası platformda gelişmeleri, süreci ve bugün ulaşılan durumu incelemeyi ve tanımlamayı amaçlamaktadır. Çalışma, belirtilen UNESCO toplantı belgeleri ve Somut Olmayan Kültürel Mirasın Korunması Sözleşmesi (2003) üzerine odaklanacaktır. Çalışmada, 2001'de Tahran'da gerçekleştirilen 'Kadınlar, Somut Olmayan Miras ve Kalkınma' başlıklı uzmanlar toplantısı kapsamında üretilen her bir bölgenin birlikte değerlendirildiği ve sentezlendiği fizibilite çalışmalarına yer verilirken, bölge özelinde üretilen fizibilite çalışmaları (http://www.unesco.org /culture/ich/index.php?lg=en\&pg=00015, 20.07.2012) dikkate alınmayacaktır. Ayrıca, 2003'teki 'Cinsiyet ve Somut Olmayan Miras' başlığıyla gerçekleştirilen uzmanlar toplantısında vurgulanan dört ana konuya ve önemli olduğu düşünülen bazı tartışmalara vurgu yapılırken, 2003’ten bugüne, SOKÜM ve kadın alanlarında yapılan birçok çalışmaya detaylı olarak yer verilmeyecektir ve bu çalışmalara sadece kısaca değinilecektir.

\section{SOKÜM ve Kadın Üzerine Tartışmalar ve Yaklaşımlar}

Birbiriyle hem ilişkili, hem de ilişkisiz gibi gözüken somut olmayan kültür mirası ve kadın temaları UNESCO ve İran Ulusal Komisyonu tarafından 1999'da gerçekleştirilen 'Somut Olma- 
yan Kültür Mirası'nın Aktarılmasında Kadının Rolü' başlıklı Sempozyum'da (1999) ilk kez uluslararası toplumun gündemine gelir. Bu toplant1, 29. UNESCO Genel Konferansı'nda (1997), İran'ın kadının SOKÜM'ün aktarılmasındaki rolünün doğru anlaşılmadığını belirttiği Tavsiye Kararı'nı temel alır. Sempozyumun temel amaçları, (1) SOKÜM'le ilgili kadının rolünün önemine ilişkin anlayışı güçlendirmek, (2) kadının SOKÜM'le ilgili rolünün korunması ve geliştirilmesi için kolaylaştırıcı ve cesaretlendirici yolları bulmak olarak tanımlanmaktadır (http://www. unesco.org/culture/ich/doc/src/00156-EN.pdf, 01.08.2012). Unutulmamalıdır ki bu tarihte, Somut Olmayan Kültürel Mirasın Korunması Sözleşmesi henüz imzalanmamıştır ve UNESCO, 'somut olmayan kültür miras' terimini 'geleneksel kültür ve folklor' terimi ile aynı anlamda kullanmaktadır. Folklor, 1989'da Birleşmiş Milletler Eğitim, Bilim ve Kültür Kurumu'nun Paris Toplantısı'nda 'Folklorun ve Geleneksel Kültürün Korunması Tavsiye Kararı'nda şöyle tanımlanmaktadir:
"Folklor (veya geleneksel ve popüler kültür) kültürel bir topluluğun, grup veya bireyler tarafindan ifade edilen ve kültürel veya sosyal kimliklerini yansittığ sürece beklentilerinin ifadesi olarak kabul edilen gelenek temelli yaratımlarının bütünüdür; folklor kalıpları ve değerleri sözlü olarak, taklit yoluyla veya farklı şekillerde aktarllırlar. Folklor biçimleri; dil, edebiyat, müzik, dans, oyunlar, mitoloji, ritüeller, gele- nekler, el sanatları, mimari ve diğer sanat dallarını içerir" (http://www. unesco.org.tr/dokumanlar/somut_olmayan_km/folklor.pdf, 25.07.2012).

Açıklanan tanımla ilişkili olarak, SOKÜM'ün çeşitli alanlarında kadının katılımının hem merkezi hem de elzem olduğu vurgulanır. Kültürün temel alanları olarak tanımlanabilecek, sıklıkla ailevi ve sosyal ilişkilerin sürdürülebilmesinin ayrılmaz parçası olan bu alanlarda, kadın çok önemli aktörlerden biri olarak kabul edilmektedir. Kadının şu temel rollerinden bahsedilmektedir:

a) Kadın, yemek, müzik, halk hekimliği ve maddi kültürün üretilmesi gibi alanlarda uzmanlık bilgisine (know-how) sahiptir ve bu özellikleriyle SOKÜM'ün koruyucusudur. Bahsedilen uzmanlık bilgisi (know-how), sadece el sanatları, halı dokumacılığı, tekstil, yaşam alanı oluşturulması ya da alet yapımıyla kısıtlı değildir. Bunların yanında, bahçecilik, tarım ve balıkçılık gibi çok çeşitli geçimlik alanlarını kapsamaktadır. Bu bilginin sahibi ve kullanıcıları olarak kadın, somut olmayan kültürün var olan biçimde üretiminin sürdürülmesinde ve geleneksel biçimlere yeni biçimlerin, tekniklerin eklenmesinde ve entegrasyonunda, diğer bir deyişle kültürün yeniden üretilmesinde çok etkilidir. Bu çerçevede, somut olmayan kültürün ifadesinin yaşatılmasında ve devamlılığının sağlanmasında kadının yaratıcılığı temeldir.

b) Kadının, somut olmayan kültürü kullanmadaki becerileri dolayısıyla, ekonomik refahın sağlanmasında rolü olduğu vurgulanır. Bu rol aslında, sadece el sanatlarının üretimi, pazarlanması ya da tarım ürünlerinin yetiştirilmesi, satımı gibi üretim ve satışla sınırlı değildir, aynı zamanda geleneksel bilgi ve uygulamaların yeniden biçimlenmesinde de etkilidir.

c) Bunun ötesinde, birçok toplulukta, kadının kendine özgü dine, töreye ilişkin bilgisi ve uygulamaları dini yaşamın en temel parçasıdır. Kadınların geleneksel dini bilgileri ve uygulamaları ahlaki değerlerle, davranış biçimleriyle, kadınla ilişkili simgelerle ve yaşam evreleriyle bütünleşmiştir. Aynı zamanda, bunlar, topluluklarda birey- 
ler arası etkileşimi, ilişkileri belirler ve bu alanlarda, kadınlar somut olmayan kültürü paylaşır ve aktarır (http://www.unesco.org/culture/ich/doc/src/00157-en.pdf, 01.08. 2012).

1999'da bir taraftan SOKÜM ve kadın arasında ilk defa bir ilişki olduğu vurgulanırken, diğer taraftan özellikle çağın dinamikleri ve etkileriyle SOKÜM'ün devamlılığının, bütünlüğünün ve varlığının tehdit altında olduğu açıklanır. Ekonomik ve teknolojik küreselleşme hızı ve etkileri somut olmayan kültür mirasını olumsuz etkilemektedir. Bu süreçte, yerel ve küresel ifade biçimlerinin değiş-tokuşu gerçekleşirken, çeşitli kültürel bilgi ve uygulamalar metalaştırılmaktadır. SOKÜM koruyucuları olarak görülen kadın, toplumların küreselleşmenin olumsuz etkilerinden korunmasına ve bu etkilere karşı savaşma biçimine derin katkılar koyacaktır. Böylelikle toplantı ile hem geniş kitlelerde kadının bu alandaki rollerine ilişkin farkındalığı arttırılacak, hem de SOKÜM'ün korunması ve güçlendirilmesiyle kültürel çeşitliliğin devamlılığına katkıda bulunulacaktır (http://www.unesco.org/culture/ich/doc/src/ 00157-EN.pdf, 01.08.2012).

Sempozyum'da yoğunlaşılan konular dört ana başlıkta toplanabilir: (1) dünyada SOKÜM'ün aktarılmasında kadının rolünün çeşitliliği ve ortak yönleri; (2), SOKÜM'ın aktarılmasında kadının rolleri arasındaki ilişkiler ile kültür ve toplumla ilgili diğer alanlar; (3), SOKÜM'ın korunması ve yeniden canlandırılması için araçlar ve yöntemler; (4), UNESCO ve üye ülkeler tarafından alınması gerekli ve acil önlemler. UNESCO İran Ulusal Komisyonu açısından bu toplantı bir fizibilite girişimidir. Bu alandaki çalışmalarla tespit edilen en önemli sorun, kadının bu mirasın aktarılmasındaki rolü üzerine farkındalığının eksik olması ve gençlerin geleneksel kültürden uzaklaşmasıdır. Bir örnekte, on iki yaş altı çocukların kültürel kavramlara aşina olmadığı belirtilmekte iken, diğer bir örnekte, İran'daki 'Nevruz' (Yeni Y1l) kutlamalarının kültürel önem taşıdığı, ancak, bugün ailelerin 'Nevruz'la ilişkili geleneklere daha az dikkat ettikleri ifade edilir. Giderek artan kültürel homojenleşme, yerel geleneklerin çeşitliliğini ve sürekliliğini tehdit etmektedir. $\mathrm{Bu}$ açıdan, fizibilite çalışması önemlidir ve toplantı bunları sağlamak için ilk adımdır (http:/wwwunesco.org/culture/ich/docsrc/00156-EN.pdf, 01.08.2012).

1999'da gerçekleştirilen toplantıda alınan karar doğrultusunda, 30. UNESCO Genel Konferans'ında kadın ve SOKÜM'le ilgili daha somut önlemleri içeren Tavsiye Kararları Taslağı'nın gündeme gelmesidir. İran'ın hazırladığı bu Taslak'ın önemli bir boyutu da, 'Kadın, SOKÜM ve Kalkınma' başlıklı dünyada altı bölgede yürütülecek fizibilite çalışmasını önermesidir. Çalışmanın beş aşamada gerçekleşmesi düşünülmüştür: (1) Farklı ülkelerdeki araştırmaların tanımlanması; (2) kadınlar ile SOKÜM arasındaki ilişki üzerine çalışan araştırmacıların saptanması; (3) bu alanda çalışan kurum ve kuruluşlarının belirlenmesi; (4) bölgesel ve bölgeler arası ağların kurulması; (5) kadın ve SOKÜM ile ilgili ayrıntılı anket çalışmasının yürütülmesi ve cevapların değerlendirilmesi. Ayrıca, okulöncesi eğitim, SOKÜM'ün alanlarına odaklanan kadın atölyeleri, kültür mirası vurgusu olan üniversite bölümlerinin kurulması, medyanın araç olarak yapılandırılması gelecek çalışmalarda dikkat edilmesi gereken alanlar ve eylemler arasındadır. Dönemin UNESCO Somut Olmayan Miras Birimi Başkanı Aikawa, "Kadınlar, Kültür Mirası ve Kalkınma" başlıklı 30. UNESCO Genel Konferansı için hazırlanan taslağın çok iddialı bir uluslararası proje olduğunu, kalkınmaya yeni boyut kazandırdığını açıklar. UNESCO'ya tarihte ilk defa bu alanları birleştiren bir proje sunulacağına işaret ederek projenin önemini vurgular (http:// www.unesco.orgculture/ich/doc/src0056-en.pdf, 01.08.2012).

1999'da atılan önemli adımın ardından konuyla ilgili ikinci vurgu, 25-27 Haziran 2001'de Tahran'da gerçekleştirilen 'Kadınlar, Somut Olmayan Miras ve Kalkınma' başlıklı uzmanlar toplantısında yapılır. Bu toplantıda, 1999'da alınan kararlar doğrultusunda gerçekleştirilen bölgesel fizibilite çalışmaları değerlendirilir. Altı bölgede (Pasifik, Afrika, Arap Ülkeleri, Latin Amerika, Asya ve Orta Asya) gerçekleştirilen fizibilite çalışmaları, üye ülkelerdeki ilgili kuru- 
luşların anketlere verdikleri yanıtlara dayanmaktadır. Bu çalışmanın, üye ülkelerdeki kadın, SOKÜM ve kalkınma konularıyla ilgili başlıca araştırma kurumlarına ilişkin genel bilgi sağladığı ve her bir bölgede gelecekte bu alanda yapılması gerekli eylemlere ve yönelimlere ilişkin tavsiyeleri içerdiği belirtilir.

2001'deki vurgu özellikle, tüm dünyada kültürel mirasın ve kültürel çeşitliliğin yaşamasında, devamlılı̆gının sağlanmasında kadının merkezde olmasıdır. Birçok kültürde temel rolü çocuk büyütmek olan kadının, annelik rolü aracıllğıyla somut olmayan mirasın çeşitli alanlarının nesiller arası aktarımını ve yenilenmesini sağlamaktadır. Mirasın devamlılığını sağlayan ve gelecek nesillere aktaran kadınlar, kültürü yeniden üretmekte ve dönüştürmektedir. Bu bağlamda, kadın ve SOKÜM ile ilgili etkinlikleri desteklemek için iki olguya dikkat edilmesi gerektiği belirtilir. Birincisi, bugüne kadar kadın ve SOKÜM üzerine sistematik araştırmaların eksik olması; ikincisi, hem yerelde hem daha geniş alanlarda, kadının rolünün ve katkısının öneminin yanlış anlaşılmasıdır (http://www.unesco.org/culture/ich/doc/src/00160-en.pdf, 01.08. 2012).

Altı bölgede gerçekleştirilen fizibilite çalışmalarında, çeşitli sorunlar ve öncelikler saptanır. Örneğin Afrika'daki sorunlardan biri, kadın ve somut olmayan mirasla ilgili çalışmalara odaklanılmaması iken, Asya'daki sorunların ülkeden ülkeye değiştiği, ancak değişime rağmen büyük kentlerdeki marketler için üretilen geleneksel el sanatları ürünlerinin üretim sürecinin kendi kültürel bağlamından koparılmasının ortak sorun olduğu açıklanmaktadır. Sorunlarla birlikte, kadın ile SOKÜM üzerine gelecek dönemlerde hazırlanması düşünülen projenin gerekçelerini sağlam temellere dayandırmak amacıyla 2001'de SOKÜM ve kadınla ilgili üç temel konuya odaklanilır (http://www.unesco.org/culture/ich/doc/src/00160-en.pdf, 01.08.2012).

Neden 'Kadın ve Somut Olmayan Miras'?

Yemek, giyim, dil, ritüeller, sözlü anlatımlar, sosyalleşme biçimleri gibi grup kimliklerini aktaran SOKÜM alanları, domestik kültürün ve ailenin önemli unsurlarıdır. Yaşayan kültürlerin ifadeleri; günlük uygulamaları ve yaşamı oluşturan, genci yetiştiren, hastayı iyileştiren, dinlenceleri sevdiren aktörlerden biri olan kadının dilinde, giyiminde, yaşamında izlenmektedir. $\mathrm{Bu}$ açıdan, kültürel kimliğin ifade edildiği alan olarak SOKÜM'ın yaşatılmasında ve korunmasında kadının önemli yeri olduğu sonucuna varılır.

Neden 'Somut Olmayan Miras ve Kalkınma'?

Çok yakın zamanlara kadar, 'kalkınma' ve 'somut olmayan kültür mirası' terimlerinin nadiren birlikte görüldüğü belirtilirken, sadece ekonomik büyümeyle özdeşleştirilen 'kalkınma'nın, ekolojik ve sosyal açıdan savunulmaz sonuçları dolayısıyla eleştirildiği açıklanır. Dünya Kültür ve Kalkınma Komisyonu'nun raporu 'Yaratıcı Çeşitliliğimiz' in (1995), ekonomi ve kültür arasındaki kavramsal ayrıma karşı durarak hem bir ilki gerçekleştirmekte, hem de kültürün, kalkınmanın önemsiz bir aracı olmadığı ve insanın özgürlüğünü, onurunu sağlamak için yaratıcı ve temel rolü olduğunu vurgulamaktadır. Yerel toplulukların uzmanlığı ve istekleriyle yönlendirilen aşağıdan yukarı kalkınma yaklaşımlarında kaynak olarak somut olmayan mirasın önemine işaret edilir. Böylelikle, birbirine oldukça aykırı kabul edilen 'kalkınma' ve 'somut olmayan miras' terimlerinin, bugüne kadar açığa çıkmamış biçimde birbirini güçlendiren nitelikte oldukları anlayışı yaygınlaşır.

Neden 'Kadın, Somut Olmayan Miras ve Kalkınma'?

1975'te Mexico City'de kadın üzerine gerçekleşen ilk Birleşmiş Milletler Konferansı ile 1995 'teki Pekin Konferansı arasındaki yirmi yıl süresince, dünyada toplumsal cinsiyet ve kalkınmayla ilgili olgular gittikçe önem kazanmıştır. Yaşayan kültürün oluşumunda, aktarıl- 
masında ve sürdürülmesinde kültür, kalkınma ve kadının taşıdığ 1 roller arasındaki etkileşim; yeni yeni hak ettiği yeri bulmaktadır. Cinsiyete duyarlı kalkınma programları, farklı cinslerin, yaş gruplarının görüşlerini içeren planlamaları tercih ederken, kültürün rolünü yeterince dikkate almamıştır. Özellikle kadınların, SOKÜM'ü esnek ve yenilikçi biçimde kullanma ve yeniden üretme yolları önemsenmemiştir (http://www.unesco.org/culture/ich/doc/src/00160-en.pdf, 01. 08.2012).

Yukarıda açıklanan üç temel konu çerçevesinde, 2001 Tahran toplantısı, 'Kadınlar, SOKÜM ve Kalkınma' başlıklı yeni projenin başlangıcı olur. Başlıca amacı, topluluklarda kadının rolünün önemine ilişkin farkındalığı artırmak ve kültüre duyarlı kalkınma faaliyetlerini geliştirmek olarak tanımlanır. Fizibilite çalışmalarıyla, kadının SOKÜM'le ilgili sosyalleşme, sanatsal ifadeler, zanaatlar, şifalandırma, sözlü edebiyat ve ekonomik hayat gibi çeşitli alanlardaki rollerine ilişkin birçok örnek sunulurken, altı bölgenin her birinin farklı gereksinimlerine göre çeşitli tavsiyelerde bulunulur. Örneğin, Afrika Bölgesi için, kadının kalkınma planlarına tam katılımı için hükümetlerin ve sivil toplumun cesaretlendirilmesi tavsiye edilirken, Orta Asya'da resmi kurumlar ile sivil toplum kuruluşları arasında ortak projelerin teşviki önerilmektedir. Hem bölgelere özel farklı vurgular, öncelikler tanımlanır, hem de bazı ortaklıklardan söz edilir. Her bölgede, SOKÜM'ün insanların günlük uygulamaları aracılığıyla değişen 'yaşayan kültürler' olarak görüldügü ve mirasın yaratıldığı, yeniden üretildiği çeşitli uygulama ve ifade alanlarında, kadının merkezde olduğu kabul edilmektedir. Ayrıca, kadını homojen bir grup olarak değerlendiren yaklaşımdan kaçınılmakta ve aralarındaki ayırıma dikkat edilmektedir. Bu çerçevede, kadın, SOKÜM ve kalkınma alanlarını kapsayacak yeni proje iki ana temaya odaklanmalıdır; (1) kadınlara özgü bilgi ve uygulamalar ve (2) kadının kültürel kaynakları harekete geçirmesi (http://www.unesco.org/culture/ich/doc/src/00160-en.pdf, 01.08.2012).

Belirtilen özelliklerin yanında, 2001'de üretimde gittikçe artan küreselleşme sonucunda, bilginin değişimi ve aktarımı ile kadının SOKÜM'le ilgili bilgi ve uygulama alanlarının birçoğundan uzaklaştığı belirtilir. Küreselleşme, bir açıdan yerel sanatlar, şifa teknikleri, müzik gibi yerel kültür ürünleri için pazarı teşvik etmekte ve böylelikle yeni geçim yolları yaratmaktadır. Diğer açıdan ise, kültürel ürünleri tüketim maddelerine dönüştüren, ticarileştiren ve yeniden tanımlayan sonuçlar doğurmaktadır. Bu yüzden, kadınların kültürel mirasın aktarılmasındaki mevcut rollerinin belgelenmesi ve artan küreselleşmeyle birlikte çelişkili ve güçlendirici öğelerin keşfedilmesi acil öncelikler olarak görülmektedir.

Fizibilite çalışmalarıyla, kadını güçlendirmeyi amaçlayan kalkınma müdahalelerinin zayıflıkları saptanır. Kadının mevcut bilgi ve çözüm üretme stratejilerinin yeterince dikkate alınmaması ise; bu zayıflıklardan biri olarak gösterilir. 2001'de SOKÜM ve kalkınmayla ilişkili olarak kadınların rolünü koruyan, canlandıran ve bu role ilişkin farkındalığı arttıracak yeni bir proje önerilir ve projenin şu amaçları taşıması tavsiye edilir:

- Kültürel açıdan duyarlı ve toplum tabanlı kalkınma yaklaşımlarını geliştirmek,

- Tüm bölgelerde, kadını hedefleyen kalkınma projelerini bilgilendirecek ve geliştirecek nitelikte bir bakışla kadına özgü SOKÜM'ü belgelemek,

- Hükümetlerdeki, hükümet dışı kurumlardaki ve şirketlerdeki karar vericilere, küresel pazar ve yerel uzmanlık bilgisi (özelikle, kadına özgü uzmanlık bilgileri) arasındaki olumlu birlikteliğin önemi konusunda duyarlılık kazandırmak (http://www.unesco.org/ culture/ ich/ doc/ src/00160-en.pdf, 01.08.2012).

SOKÜM ve kadın alanlarında yukarıda bahsedilen vurgular sonrasında, 2003 yılında "Somut Olmayan Kültürel Mirasın Korunması Sözleşmesi”nin kabul edildiği bilinmektedir. Bugüne kadar 'folklor' kavramılla eşdeğer tanımlanan "Somut Olmayan Kültürel Miras" kavramı, bu 
Sözleşmede '...toplulukların, grupların ve kimi durumlarda bireylerin, kültürel miraslarının bir parçası olarak tanımladıkları uygulamalar, temsiller, anlatımlar, bilgiler, beceriler ve bunlara ilişkin araçlar, gereçler ve kültürel mekanlar anlamına gelir' ifadesi yer almaktadır (http://www. unesco.org.tr.dokumanlar/somut_olmayan_km/sokm_korunmasi.pdf, 02.08.2012). Bu sözleşme, metninde önceki toplantılardan farklı olarak 'kadın' teriminin hiç kullanılmadığını görüyoruz. "Somut Olmayan Kültürel Mirasın Korunması Sözleşmesi”nin taslak hazırlıklarında, 'kadın' teriminin kullanımıyla ilgili tartışmalar yapıldığ 1 bilinmektedir. Tartışmalarda iki farklı görüşe odaklanılır. Görüşlerden birinde, kadının somut olmayan mirasın aktarılmasında özel bir rolü olduğu ve bu role özellikle dikkat edilmesi gerektiği vurgulanırken, diğerinde, bahsedilen vurguya izin verilmemesi gerektiği çünkü bunun kadına yönelik pozitif ayrımcılık olacağı ifade edilir. Sonuç olarak, kadına yönelik pozitif ayrımcılık yapmama adına 'kadın' terimine "Somut Olmayan Kültürel Mirasın Korunması Sözleşmesi”nde yer verilmez. Bugün, Sözleşme metninde 'kadın’1 da içeren ‘topluluk', 'grup' ve 'birey’ kelimeleri kullanıldığı görülmektedir.

SOKÜM alanında, kadın ve erkek arasında sıklıkla farklı rollerin ve işbölümünün gözlemlendiği, bu tür farklılıkların ilgili topluluk tarafindan kabul edilmesine rağmen, bazen UNESCO tarafından insan hakları açısından tartışmalar doğurduğu açıklanır. Bu tür deneyimler ve tartışmalar sonucunda, UNESCO, sözleşmeyle ilişkili olarak bazı soruları gündeme getirir; Somut Olmayan Kültür Mirası ne ölçüde cinsiyete özel uygulamalara ve aktarımlara dayanmaktadır? Çağdaş toplumlarda, somut olmayan mirasın kadın aktarıcılarının anlaşılması ve teşviki kadının güçlenmesine katkıda bulunur mu? Cinsiyet eşitliği kavramı geleneksel kültür ve yaşam tarzlarının korunmasıyla her zaman uyumlu olabilir mi? SOKÜM alanında cinsiyet olgusunu nasıl yerleştirmeliyiz? (http://www.unesco.org/culture/ich/doc/src/00125-en.pdf, 01.08.2012). Bu gibi

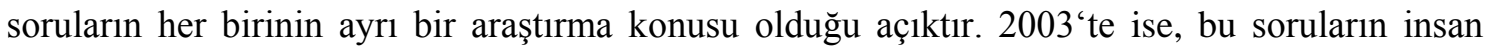
hakları düşüncesiyle uyumluluğu olan, gerçekliği ve anlamı olan çözümleri bulmak için değerlendirilmesi gerektiği açıklanır. Bu gelişmelerle ilişkili olarak, 2003'te Paris'te 'Cinsiyet ve Somut Olmayan Miras' başlığıyla gerçekleştirilen uzmanlar toplantısı düzenlenir. Toplantı'da, cinsiyet sorunu incelenir ve SOKÜM'le ilgili (1) içerdeki/öteki; (2) geleneksel ve modern; (3) aktarım ve koruma ve (4) somut olmayan mirasta cinsiyet eşitliği/eşitsizliği olmak üzere dört temel konuya odaklanılır.

'İçerdeki/Öteki’ başlığı altında, SOKÜM ve korunması ile ilgili temel sorunun, yaklaşımın kimin görüşü ('içerdekiler'in mi? ya da 'ötekiler'in mi?) temel alınarak yapılacağıyla ilgilidir. SOKÜM'ün statik olmadığına, değiştiğine, sürekli yeniden yorumlandığına ve yeniden oluşturulduğuna dikkat çekilir ve bunun her zaman mirasın koruyucuları tarafından yapılmadığı, bazen 'ötekiler' tarafından yapıldığı vurgulanır. Bir açıdan, kamuya açılacak mirasın, koruyucular tarafından seçilmesine ilişkin genel bir yaklaşımın varlığından söz edilir. Diğer açıdan ise, bunun aslında kültürlerin sahiplerinin kim olduğuyla ve korunacak özgünlügün ne olduğuyla ilişkili olduğuna vurgu yapılır. Hatta 'öteki'lerin belirli bir kültürel ifadeyi oluşturma becerisini öğrenmesi ve iyi uygulaması durumu ele alınarak, topluluğun bu yeni uygulayıcıları ne derece mirasın özgün koruyucuları olarak kabul edeceği sorgulanır. Bilginin 'öteki' ile paylaşılmasının 'öteki'ne mirasın sahibi olma hakkını vermeyeceği sonucuna varılır (http://www.unesco.org/culture/ich/ doc/src/00125-en.pdf, 01.08.2012).

'Aktarma ve Koruma' kapsamında, SOKÜM'ün korunmasının ve tanımlanmasının geniş ölçüde politik bir süreç olduğuna işaret edilir. Koruma eyleminin ve eylemin önemli öğelerinden belgelemenin kaçınılmaz olarak mirası kamusallaştırdığı ve korumanın, sıradan olanı sıra dışına dönüştürme özelliğinden söz edilir. Bir taraftan, bunun kadınlara olumsuz yan etkileri olabileceği ve kadına özgü mirasın vurgulanmasıyla kadının geçmişe ve toplumdaki eski konumuna taşınabileceği belirtilir. Aksi taraftan ise, toplumda kadına özgü mirasın dikkate alındığ1 
koşulda, kadının toplumdaki konumunun yükselmesine ve güçlenmesine olumlu katkıları olabileceğinden bahsedilir. Her iki durumda da, SOKÜM'ün koruması sonrasında kadının durumunun ve toplumdaki yerinin öncesiyle aynı olmadığına vurgu yapılır.

Somut olmayan mirasta cinsiyet eşitliği/eşitsizliği konusunda güç olan, kadın ve erkeğin farklı rollerinin kavranmasıdır. Sözleşme de, belirli bir kültürel ifadeye baktığımızda, cinsiyet rolleri arasında birçok dengesizlik bulunduğu ve SOKÜM'ün, zorunlu olarak kadın ve erkek tarafından aynı şekilde ifade edilmediği, aktarılmadığı ve korunmadığı belirtilir. Ancak, sosyal, kültürel gelenekler ve topluluktaki tüm uygulamalar daha geniş kapsamda ve bakışla ele al1nırsa, kadın ve erkeğin rollerinin farklı ve ilişkilerinin daha dengede olduğu ifade edilebilir. Bunun aslında eşitsizlik mi?, eşitlik mi? ya da hiçbiri mi? olduğu sorgulanır. Bu sorgulamayı aydınlatmak için, 'eşitsizlik' teriminin kullanılmaması gerektiği belirtilirken, aslında bunun, üstünlük/aşağılık meselesi olarak ele alınmaması ve 'güç' kapsamında değerlendirilmemesi gerektiği belirtilir. Hükmedici ve aşağılayıcı olmayan gücün eşitsizlik sorunu olarak görülmemesi vurgulanır. Ayrıca, nasıl bir eşitsizlikten bahsedildiği tartışılarak, sorunun 'mirasın aktarılma, korunma biçimlerinde gözlemlenen eşitsizlik mi?' yoksa, 'eşitsizlik'i saptayanlar ('İęerdekiler mi?'/'Ötekiler mi?') tarafından belirlenen eşitsizlik mi?' olduğu irdelenir. Ayrıca, topluluklardaki cinsiyet eşitliği/eşitsizliğiyle ilgili farklı anlayışlar konusunda dikkatli olmak gerekliliğine işaret edilir (http://www.unesco.org/culture/ich/doc/src/00125-en.pdf, 01.08. 2012).

2003 Paris Toplantısı'nda, SOKÜM'ün korunmasında genellikle Avrupa/Amerika kökenli Batı gözüyle analiz ve belgelemenin hakim olduğu eleştirisine yer verilir. Cinsiyet eşitsizliği tanımı ve anlayışının, Batılı görüşlerden ve teorilerden etkilendiğine vurgu yapılır. Batı'da kabul gören cinsiyet rolleri ve değerlerinin, korunması gerekli kültürel elemanlar olarak kabul edilen diğer cinsiyet sistemleri üzerinde olumsuz ve tehlikeli etkileri olmaktadır. Eğer, Batılı bakış açıları politik eylem olarak korumanın bir parçası olacaksa, durumu tümüyle farklı yerlerden analiz edecek başka politik çabalara ihtiyaç duyulması gerekmektedir. Bu çerçevede, SOKÜM'ün ifadesi cinsiyet farklılıklarını yansıtabilir. Topluluklardaki cinsiyet ve cinsiyetler arası dengeleri öne çıkaran yorumların dikkate alınması gerekmektedir.

Tartışmalarla, SOKÜM'ün aktarılmasında kadınlara yönelik bir eşitsizlik olduğuna dair herhangi bir evrensel sebep olmadığına dair bir sonuca varılır. Aksine, bu miras aktarımının sonucu olarak, özellikle yerelde, farklı cinsiyet rollerinin karmaşıklığının yerel, milli ve uluslararası gündemde alevlendirilmesiyle cinsiyet eşitsizliğine sebep olunabileceğine vurgu yapılır. 2003 Paris Toplantısı sonucunda, UNESCO için altı maddeden oluşan tavsiye kararları alınmıştır. Kararlardan aşağıda açıklananların doğrudan cinsiyet ve somut olmayan mirasla ilgili olduğu saptanmıştır.

- SOKÜM'ün korunması, cinsiyet (toplantı belgesinde 'cinsiyet', her bir cinsle bağlantıl1 özellikler, işler, roller ve kimlikler olarak tanımlanmaktadır. Hem kadın ve erkek olarak iki cinsle, hem de cinsiyet değiştiren ve çift ruhlu gibi farklı tanımlamalarla açıklanır) uygulamalarının ve temsillerinin anlaşılmasınıve kültürlerin karşılaştığı süreçlerin ve mekânların önemli görülmesini içermelidir,

- SOKÜM'ün bir öğesi olarak cinsiyet eşitsizliği, korunan ve aktarılan kültürel ilkelerin (konuşulan ve yazılı somut ve somut olmayan mirasın ifadeleri olarak toplamı) parçası olarak değerlendirilmelidir,

- Yerel, bölgesel ve ulusal seviyede karar vermede sıklıkla erkeklerin egemen olduğu ve bu durumun değiştirilmesi için yollar bulunmalıdır,

- SOKÜM'ün tanımlanması, belgelenmesi ve hatta korunması için politika oluşturulmasında, mirasın koruyucuları olarak kadınların ve kadın araştırmacıların katılımı tavsiye edilir (http:// www.unesco.org/culture/ich/doc/src/00125-en.pdf, 01.08.2012). 
Özetle, uluslararası platformda doğrudan kadın ve SOKÜM'le ilgili yapılan bu toplantılarda, kadının somut olmayan mirasın üretilmesinde, korunmasında ve nesillerarası aktarılmasında rolünün önemi üzerine odaklanılmaktadır. 1999'da gerçekleştirilen Tahran Toplantısı'yla, uluslararası ölçekte kadın ve SOKÜM'le ilgili fizibilite çalışmalarına ilk adım atılmıştır. Aikawa'nın ifade ettiği gibi tarihte ilk defa kalkınmaya yeni boyut kazandıran bir projeyle somut olmayan miras, kadın ve kalkınma birlikte ele alınmıştır. 2001'de, bu üç alan (SOKÜM, kadın ve kalkınma) arasındaki ilişkiler irdelenerek, bu mirasın hem kalkınma, hem de kadının toplumda güçlenmesi için kaynak olduğu vurgulanır. Paris Toplantısı'nda (2003a) ise SOKÜM'ın korunmasının Batılı gözüyle analizlere, belgelemeye dayandığı ve bu yaklaşımın, korunmaya değer görülen kültür elemanları olarak mevcut cinsiyet sistemlerini olumsuz yönde etkilediği belirtilir. SOKÜM'ün öğesi olan alanlarda cinsiyet eşitsizliğinin, korunan ve aktarılan kültürel ilkelerin parçası olarak değerlendirilmesi önerilir."Somut Olmayan Kültürel Mirasın Korunması Sözleşmesi”nde 'kadın' terimine yer verilmediği tekrar vurgulanmalıdır.

2003 'ten sonra gerek kadın, gerekse somut olmayan kültür miras alanlarında yapılan çalışmalarda genellikle 'toplumsal cinsiyet eşitliği' terimine yer verilmektedir. Sonraki yıllarda yapılan çalışmalarda, UNESCO'nun özellikle kadın çalışmalarında ve kadınla ilgili oluşturduğu gündemde 'toplumsal cinsiyet eşitliği'ne vurgu yaptığı izlenmektedir. Örneğin, 2008 ve 2009 yılları Dünya Kadınlar Günü toplantılarının toplumsal cinsiyet eşitliği teması üzerinden yapıldığ 1 görülmektedir (http://www.unesco.org/new/index.php?id=34611 GenderEquality, International Women's Day 2008 \& Internatioonal Women's Day 2009, http://www.unesco .org/ new/index.php?id=34612 GenderEquality, 01.09.2012).

Bugün gelinen noktaya baktığımızda ise, 2008-2013 UNESCO Program'ında toplumsal cinsiyet eşitliği iki küresel öncelikten biri olarak belirlenmiştir. 2008-2012 Toplumsal Cinsiyet Eşitliği Eylem Planı, eğitim, sosyal ve beşeri bilimler gibi farklı alanlarla birlikte kültür alanında da kadının güçlenmesinin takibini ve cinsiyet eşitliği çabalarına UNESCO programlarının ve teşebbüslerinin tümüyle ve aktif olarak katılımını sağlamak için UNESCO'nun yapacağ eylemleri tanımlar (http://www.unesco.org/new/en/unesco/themes/gender equality/features/unesco -priority-gender-equality-action-plan-2008-2013, 01.08.2012). Bu kapsamda, 2012-2013 programında geliştirilen stratejide kültür alanında somut olmayan kültür mirası ve kadının birlikte vurgulandığı görülmektedir. Stratejide bu alanla ilgili yapılan vurgular şöyle özetlenebilir: (1) UNESCO'nun somut ve somut olmayan kültür miras alanları, müzeler, kültür politikaları gibi alanlarla ilgili yaptığı çalışmalar vasıtasıyla küresel ölçekte cinsiyet konularına öncelik vereceği; (2) UNESCO, kadın ve kızları ulusal ve uluslararası seviyede kültür, doğal ve somut olmayan mirasın korunmasında ve yönetiminde daha geniş katılıma hazırlayarak, onların kapasitesini geliştirmeye odaklanan kültür mirası politikalarında cinsiyet eşitliği üzerine ana eylemlerini sürdürecektir; (3) Özel çabalar, kadının yaşayan mirasın korunmasına katılımı ile gücünü arttırmayı hedefleyecektir; (4) Yaratıcı endüstriler alanındaki eylemler, zanaatların sosyo-ekonomik etkisini arttırmanın arayışında olacaktır ve özellikle kadının sosyal ve ekonomik güçlenmesine katkıda bulunmak için kadınlara öncelik verecektir (http://www.unesco.org/new /en.Culture/about-us/how-we-work/strategy/global-priority-gender-equality, 01.09.2012). Bu strateji, küresel ölçekte kadın ve SOKÜM'ün tekrar birlikte vurgulanması, bu alanın sadece SOKÜM'ün korunmasını ve kadınların SOKÜM alanları ile topluluklarda güçlendirilmesini sağlamakla sınırlı görülmediğini, toplulukların mutluluğunun ve refahının sağlanmasına katkısı olacak bir alan olarak kabul edildiğini göstermektedir. 


\section{Sonuç}

1999 'da on iki ülkenin temsilcilerinin katılımıla birlikte ele alınan iki alan 'SOKÜM' ve 'kadın'ın, bugün UNESCO tarafından küresel önceliklerden biri olarak tanımlanan 'cinsiyet eşitliği' kavramının gelişmesine ve kalkınmanın yeni boyut kazanmasına önemli katkıları olduğunu söylemek mümkündür. Özellikle kadınların etkin role sahip olduğu alanlarda somut olmayan miras alanlarının korunması, yaşatılması ve gelecek nesillere aktarılmasında kadının taşıdığ rolün önemini tartışmasız kabul etmek gerekir. İki alanın 'SOKÜM' ve 'kadın'ın birlikteliğinin, hem toplumda kadınların güçlenmesine, hak ettikleri yeri almalarında, hem de kültürel çeşitliliğin sürdürülerek gelecek nesillere aktarılmasında ve toplumsal kalkınmanın sağlanmasında eşsiz firsatlar sağladığı ortadadır. Bu bağlamda, somut olmayan kültür mirasının korunması için topluluklara özgü bilgi ve uygulamaları harekete geçirmek ve özellikle kadını bu alanda teşvik etmek elzemdir. Uluslararası ölçekte yapılan bu çalışmaların önümüzdeki yıllarda, SOKÜM'ün gelecek nesillere aktarılmasına ve kadınların güçlenmesine, dolayısıyla da toplumların daha yüksek mutluluk ve refah seviyesine ulaşmasına büyük katkılar sağlayacağını ümit etmek mümkündür. Ayrıca, SOKÜM'ün korunmasında kadının rolü ve katkılarının önümüzdeki yıllarda da konuşulacağı öngörülebilir.

Türkiye özelinde ise, SOKÜM'ün sözlü anlatımlar, sözlü gelenekler, toplumsal uygulamalar, ritüeller ve el sanatları geleneği gibi çeşitli alanlarını düşündügümüzde, kadınlara özgü bilgi ve uygulamaların Anadolu'nun somut olmayan kültür mirasında özel bir yeri olduğunu belirtmek mümkündür. Kadına özgü bu bilgi ve uygulamaların harekete geçirilmesi ve teşvik edilmesi sadece kadının güçlenmesine ve SOKÜM'ün gelecek nesillere aktarılmasına katkı yapmakla sınırlı değildir. Bu çalışmaların, Anadolu'daki kültürel çeşitliliğin devamının sağlanmasına, hoşgörü ortamının pekişmesine, toplumsal mutluluğa olumlu etkiler sağlayacağ vurgulanmalıdır. 


\section{KAYNAKÇA}

Oğuz, M. Ö. (2010). Turkey’s Intangible Cultural Heritage. Ankara: Kültür ve Turizm Bakanlığı Yayınları.

Oğuz, M. Ö. (2009). "Somut Olmayan Kültürel Miras ve Kültürel İfade Çeşitliliğì”. Millî Folklor, 82, 6-12.

Culture, Strategy-Global Priority Gender Equality. (2012, 1 Eylül). Kaynak: http://www.unesco.org/new en/culture/about-us/how-we-work/strategy/global-priority-gender-equality/

Gender Equality, International Women's Day 2008. (2012, 1 Eylül). Kaynak: http://www.unesco.org/new /index.php?id=34611

Gender Equality, International Women's Day 2009. (2012, 1 Eylül). Kaynak: http://www.unesco.org/new/ index.php?id=34612

Meetings (co-)organized by the Section of Intangible Cultural Heritage. (2012, 1 Ağustos). Kaynak: http://www.unesco.org/culture/ich/index.php?lg=en\&pg=00015

UNESCO Priority Gender Equality Action Plan 2008-2013. (2012, 1 Ağustos) Kaynak: http://www.unesco.org.new/en/unesco/themes/gender-equality/features/unesco-priority-gender-equalityaction-plan2008-2013/

Synthesis Report, Activities in the Domain of Women and Intangible Heritage. International editorial meeting and future activities in the domain. Iran National Commission for UNESCO, Tehran June 2001 (June 2001). (2012, 1 Ağustos). Kaynak: http://www.unesco.org/culture/ich/doc/src/00160-en.pdf

Final Report, International Symposium on the Role of Women in Transmission of Intangible Cultural Heritage (27- 30 September 1999 [1999a]). (2012, 1 Ağustos). Kaynak: http://www.unesco.org /culture/ich/doc/src/00156-en.pdf

International Symposium on the Role of Women in Transmission of Intangible Cultural Heritage 27-30 September 1999, Agenda (27 - 30 September 1999 [1999b]). (2012, 1 Ağustos). Kaynak: http:/www. unesco.org/culture/ich/doc/src/00158-en.pdf

International Symposium on the Role of Women in Transmission of Intangible Cultural Heritage (27- 30 September 1999 [1999c]) Tehran, Iran, Annoted Agenda. (2012, 1 Ağustos). Kaynak: http//www unesco.org/culture/ich/doc/src/00157-en.pdf.

Final Report, Expert Meeting Genderand Intangible Heritage (8-10 December 2003 [2003a]). (2012, 1 Ağustos). Kaynak:http://www.unesco.org/culture/ich/doc/src/00125-en.pdf

Somut Olmayan Kültürel Mirasın Korunması Sözleşmesi. (2012, 2 Ağustos). Kaynak: http://www.unesco.org.tr/dokumanlar/somut_olmayan_km/sokm_korunmasi.pdf 